\title{
Corporate Management of Highly Dynamic Risks: Evidence from the Demand for Terrorism Insurance in Germany
}

\author{
Christian Thomann ${ }^{\mathrm{a}, \mathrm{b}}$, Razvan Pascalau ${ }^{\mathrm{c}}$ and \\ J.-Matthias Graf von der Schulenburg ${ }^{a}$ \\ ${ }^{a}$ Institute for Risk and Insurance, Leibniz Universität Hannover, Königsworther Platz 1, Hannover \\ 30167, Germany. \\ E-mail: ct@ivbl.uni-hannover.de \\ ${ }^{\mathrm{b}}$ Ministry of Finance, Financial Institutions and Markets, Stockholm S-103 33, Sweden. \\ ${ }^{\mathrm{c}}$ Department of Economics and Finance, SUNY Plattsburgh, 101 Broad Street, Redcay Hall 124, \\ Plattsburgh, NY, 12901, U.S.
}

This paper investigates a corporation's risk management response to highly dynamic risks. Using a unique data set on the German terrorist insurance market, the paper tests whether corporate risk managers have a clear understanding of the probability distribution of highly dynamic risks or if risk managers learn from severe losses and base their decisions upon day-to-day experience. The paper further investigates whether risk managers become more confident in their risk management decisions over time. For this purpose, we apply Viscusi's prospective reference theory to a corporate context. We find that firms learn from single events when making their risk management decisions, and that risk managers become more confident with their risk management decisions over time.

The Geneva Risk and Insurance Review (2012) 37, 57-82. doi:10.1057/grir.2011.3; published online 28 June 2011

Keywords: corporate insurance; risk management; terrorism insurance; expected utility; prospect theory

\section{Introduction}

Recent developments, such as the financial crisis and the emergence of terrorism as a global security problem, serve as a reminder that corporations face a large number of highly dynamic risks. However, the literature on corporate risk management largely assumes that risks are stable over time. According to our knowledge, there is no (empirical) research on how corporations process the inflow of new information on risks that may themselves be subject to drastic changes over time. We refer to these risks as dynamic risks.

The present paper aims to close the gap in the literature on corporate risk management by proposing some theoretical considerations of how 
corporations process new information on dynamic risks. Using a unique data set on the demand for terrorism insurance in Germany, we are able to test if corporations learn from single loss events and if they grow confident in their assessment of a highly dynamic risk.

Corporate risk managers buy insurance according to their assessment of risks, for example their estimates of losses and probabilities. If a risk manager's assessment of risk is well-founded, then the loss experience over a short period of time, that is the occurrence of losses or, equally, their absence, will not lead to a change in a firm's demand for insurance. However, if there is only little relevant data to assess the risk or the probability distribution of a potential loss, every new information is most likely to shift the probability distribution of risk managers such that single events may lead to changes in the insurance demand.

Our analysis is divided into three sections. First, we refer to the theory of corporate risk management. We then present some theoretical considerations concerning the way corporations process new information on dynamic risks. These considerations are based on Viscusi's ${ }^{1}$ prospective reference theory. We argue that Viscusi's ${ }^{1}$ prospective reference theory that has originally been developed for individual decision-making can be extended to a corporate context. Finally, we derive two hypotheses that we verify empirically.

Second, we discuss the nature of terrorism and the institutional arrangements of corporate terrorism insurance in Germany. We introduce our data set that contains firm-level information on all terrorism insurance purchases through the single German government-sponsored terrorism insurer. The data set spans the period from November 2002 until March 2007. During this period, corporations in Germany were confronted with inconclusive information about their terrorism exposure. After September 11, 2001 (henceforth 9-11) and until March 2004, Western Europe and North America were spared from large terrorist attacks. Since then, terrorists have successfully targeted Spain and the United Kingdom, and a number of failed plots have been reported in Germany, several other European countries, and the United States. The data have a few characteristics that make them particularly suited for our analysis. Among them is the fact that the terrorism insurer did not change its prices during the observation period and that the insurance premium considers only very few factors.

Third, we proceed with our empirical investigation that considers both aggregate and firm-level demand for terrorism insurance through the government-sponsored terrorism insurer. For instance, we test if recent terrorist activity has a significant impact on the demand for terrorism

\footnotetext{
${ }^{1}$ Viscusi (1989).
} 
insurance. Further, using firm-level data, we examine whether risk managers become more confident in their risk management decisions and how the willingness to reverse past risk management decisions changes over time.

The main results of the analysis are the following. First, we find evidence that corporations learn about their probability of falling victim to a dynamic risk using a mechanism that allows for dynamic updating. Recent attacks and the amount of time that has passed since 9-11 have significantly influenced firms' risk management decisions. Second, firms become more confident in their risk management decisions over time, while the willingness to reverse past risk management decisions decreases. Thus, once firms become more familiar with terrorism risk they treat the risk less like a highly dynamic risk.

\section{Theory of risk management and its extension to dynamic risks}

There is an extensive and huge debate in the literature regarding why firms' risk management differs from that of risk averse individuals. ${ }^{2}$ Without repeating this debate, we know that due to different kinds of transaction costs corporations try to maximize a concave function. Thus, although a firm's shareholders can diversify risks on financial markets, the firm still behaves as if it were risk averse. This behaviour is reinforced by the particular role that the individuals comprising a firm's management play for the firm's risk management decisions. ${ }^{3}$

This implies that the results derived from the expected utility model might also hold in a corporate environment. The classic theory on insurance demand, that is Schlesinger, ${ }^{4}$ assumes a given loss probability distribution. The consequence of this assumption is that single losses should not change the demand for insurance if insurance premiums are constant. Yet, this may not necessarily hold if the risk manager is confronted with a dynamic risk that is subject to drastic changes. Hence, for dynamic risks, risk managers might have little experience, such that single losses may change the assessment of those risks, and consequently the demand for insurance. This learning process on probabilities is reflected in Viscusi's ${ }^{1}$ prospective reference theory. ${ }^{5}$

\footnotetext{
${ }^{2}$ See MacMinn and Garven (1999) for a discussion and references. See Cole and McCullough (2006) for a recent study on insurers demand for (international) reinsurance.

3 This argument is also stressed by Aunon and Ehling (2008). Further, in an empirical study Hoyt and Khang (2000) find that managerial entrenchment has significant impact on a firms' insurance demand.

${ }^{4}$ Schlesinger (2000).

${ }^{5}$ Behavioural economists have shown that individuals use a number of heuristics when assessing the probability of rare occurrences. Among them is the well-known availability heuristic (Tversky and Kahneman, 1973).
} 
Prospective reference theory assumes that decision-makers use a dynamic Bayesian process to determine the probability of uncertain events. In the bivariate model of Viscusi's ${ }^{1}$ prospective reference theory, the decision-maker has a prior belief of an event's probability $(q)$. This prior belief is weighted with a parameter $\gamma$. This parameter corresponds to the individual's confidence in its prior belief. In the periods after this prior belief have been formed, the decisionmaker views $\xi$ additional trials. In these trials, he observes the outcome in question $z$ times. As a result of his prior knowledge, the number of additional trials, and their outcomes, the decision-maker then forms a posterior probability $p^{*}$. One obtains this posterior probability by combining the prior information $q$ and $p$, where $p$ denotes the number of outcomes $(z)$ divided by the additional number of trials $(\xi)$. In turn, $p$ is then weighted using $\xi$ :

$$
p^{*}=\frac{\gamma q+p \xi}{\gamma+\xi} .
$$

The posterior probability $p^{*}$ can be used to generalise the expected utility model. ${ }^{6}$ It has, as Viscusi (p. 237) ${ }^{1}$ stresses "the same mathematical properties as a standard probability measure".

Prospective reference theory has been empirically tested in a number of studies. ${ }^{7}$ Viscusi and O'Connor ${ }^{8}$ analyse the risk assessment of workers in the chemical industry. In their study they provide workers, who had previous experience with handling chemicals, with additional information (hazard warnings) on new chemicals that were to be used on their job. They find that even very experienced workers place a great weight on the new information about dangerous chemicals. The posterior probability is greatly influenced by the new information $\left(\xi / \gamma\right.$ is very large). Viscusi and Evans ${ }^{9}$ extend the analysis of workers' decision processes to reflect the significantly different probabilities reported by workers and those implied by their behaviour. Jakus and Shaw ${ }^{10}$ find that hazard warnings influence anglers' choices by investigating the impact of fish consumption advisories on recreational fishing. More specifically, they observe that an increasing severity of hazard warnings leads to higher perceived risk. Considering that terrorism risk has changed dramatically and that terrorism has had a great influence on society, it provides an interesting case of how corporate risk management reacts to a dynamic risk.

\footnotetext{
${ }^{6}$ See Viscusi (1989) for an in-depth discussion of the predictive power of prospective reference theory.

${ }^{7}$ Nevertheless, there exists, as Harless (1993) shows, some experimental evidence that the predictions of the prospective reference theory are violated in lottery experiments.

${ }^{8}$ Viscusi and O'Connor (1984).

${ }^{9}$ Viscusi and Evans (2006).

${ }^{10}$ Jakus and Shaw (2003).
} 


\section{Terrorism and terrorism insurance in Germany}

\section{Terrorism risk}

The 9-11 terrorist attacks have created an unprecedented level of destruction. Using civilian aircraft against buildings, the terrorists killed $2,871^{11}$ people, destroyed or severely damaged 31.1 million sq.ft. of office space ${ }^{12}$ and caused one of the most expensive insured losses in history. The inflation adjusted insured damage of 9-11 is only surpassed by the losses from the hurricanes Katrina, 2005, and Andrew, 1992. ${ }^{13}$ The bombings in Madrid in 2004 and London in 2005, and a number of attempted attacks have since then served as reminders that the struggle against terrorism is going to last a long time. Governments have responded to the terrorist threat by passing legislations aimed at protecting citizens, engaging in military operations, increasing defense spending, and by intervening on the terrorism insurance markets. Yet, terrorism does not only affect governments. It is also a major challenge for corporate risk managers. This challenge is to a large part due to the more recent changes in terrorists' tactics.

United States Department of State ${ }^{14}$ provides a commonly used definition of terrorism: Terrorism is the "premeditated, politically motivated violence perpetrated against noncombatant targets by subnational groups or clandestine agents, usually intended to influence an audience". Terrorism itself is not new, although its nature has changed drastically. Over the last 20 years, terrorists' motivations, organisational structures, and goals have evolved. From the 1960 s to the 1980 s, terrorism was predominately inspired by separation, racism, Marxist ideology, nationalism, and economic inequality. ${ }^{15}$ The respective groups, among them the German "Red Army Faction", were characterised by well-defined command and control structures. They had distinct objectives and their trained members were full-time planning, preparing, and executing attacks. ${ }^{16}$ Owing to these characteristics, terrorism was considered to be a mainly domestic and regional risk. With the exception of countries like Great Britain, Spain, and South Africa with a history of regional conflicts, terrorism was included in standard fire insurance contracts.

Today terrorism is no longer seen as mainly a domestic risk. During the last decades, additional motives for terrorism have appeared, different kinds of organisational structures have emerged, and terrorists' actions have gained

\footnotetext{
11 National Obituary Archive-Honor Roll (2007).

${ }^{12}$ Fuerst, 2005.

13 Swiss Re, 2006.

${ }^{14}$ United States Department of State (2004, p. xii).

${ }^{15}$ Wilkinson, 1986.

${ }^{16}$ Hoffman, 1997.
} 
lethality. ${ }^{17}$ Moreover, as discussed in Enders and Sandler ${ }^{18}$, the 1979 takeover of the American embassy in Teheran marked the rise of a new kind of terrorism that aims at establishing an Islamic state. The shift towards religiously-inspired terrorism, that is Rapoport's " "Fourth Wave", has significant implications for potential attacks because religious groups might even view civilians to be legitimate targets. These authors argue that post Cold War terrorist groups have also become more amorphous: their members are often times living "regular" lives, and international networks, such as Al-Qaeda, have gained importance. Terrorism's highly dynamic ${ }^{20}$ nature sets terrorism apart from most other risks that corporations face.

As terrorism is a highly dynamic risk, we hypothesize that corporations' risk management decisions are governed by a process that allows for learning. A process that allows for a dynamic updating of probabilities is Viscusi's 1 prospective reference theory. Applying this theory to the risk managers' decision problem of how to insure against terrorism we expect to observe two effects:

Claim 1 (A) Learning Hypothesis: Recent terrorist activity has a strong influence on the demand for terrorism insurance. Thus, if firms believe that their knowledge of terrorism risk is not well-founded we would expect them to update their terrorism risk management. Expressed in terms of the prospective reference theory, (A) tests if $\xi_{i}>0$.

Claim 2 (B) Confidence Hypothesis: Firms will grow more confident in their risk management decisions over time. If this is the case we would expect that over time firms will start to treat a dynamic risk in a similar manner to a more conventional risk. Expressed in terms of the prospective reference theory, (B) tests if $\xi / \gamma$ decreases over time the more a firm has been insured against terrorism. $^{21}$

\section{Institutional arrangements for terrorism insurance in Germany}

The events of 9-11 have resulted in important changes on terrorism insurance markets in a number of countries including Germany. Before this date

\footnotetext{
17 Enders and Sandler, 2000.

${ }^{18}$ Enders and Sandler (2006, pp. 47-50).

${ }^{19}$ Rapoport $(1984,2004)$.

${ }^{20}$ Kunreuther et al. (2003) use the term "dynamic uncertainty".

${ }^{21}$ More precisely, $\gamma$ marks the weight of the prior information collected in periods $0, \ldots, t-1$, while $\xi$, on the other hand, marks the weight of the new information available in period $t$.
} 
terrorism claims in Germany were regularly included in standard fire insurance contracts. ${ }^{22}$ Although discussions about excluding terrorism risk from regular insurance contracts can be found in the German insurance literature from the 1970 s and 1980s, a period during which the country experienced a number of terrorist attacks (i.e., the attacks on the Olympic Games in Munich, 1972, and various attacks conducted by the leftist Red Army Faction), the insurance industry saw no need to exclude these risks from standard fire insurance contracts. ${ }^{23}$ Since terrorism risk was covered by a corporation's fire insurance contract, risk managers did not need to treat terrorism risk separately. However, 9-11 heavily affected Munich Re and Allianz. ${ }^{24}$ As a consequence, starting from January 2002, terrorism risk was excluded from commercial fire insurance contracts in Germany and the German government intervened by offering reinsurance coverage for terrorism insurance.

Although Germany is not the only country where the government reinsures terrorism risk, there are some particularities that distinguish the country's terrorism insurance scheme. ${ }^{25}$ Owing to the regulation in Germany, governmentsponsored terrorism insurance is only available from one insurer, Extremus AG. Extremus AG, a public-private partnership, was founded in 2002, and is owned by 16 private insurance companies. Extremus is 100 per cent reinsured for claims up to $€ 10$ billion. The layer up to $€ 2$ billion is provided by the private insurance market. The layer between $€ 2$ billion and $€ 10$ billion is reinsured by the German government. Corporations interested in governmentbacked terrorism insurance must purchase their coverage through Extremus. The terrorism insurance contracts are highly standardised. ${ }^{26}$ Thus, they allow us to compare purchasing patterns over time.

The primary insurance contracts offer compensation for property losses (buildings and content), direct business interruption losses, and clean-up costs caused by an act of terrorism. The contracts are designed as upper limit policies. For this type of contract the policyholder's payout is the minimum of the loss due to a terrorist attack, and the upper limit $(U L)$ selected when purchasing the contract. Another particularity of the German terrorism insurance scheme is that only very few risk characteristics are used to determine the terrorism insurance premium. The premium is calculated mainly by accounting for the policyholder's maximum possible loss $(M P L)$ a number that

${ }^{22}$ Exclusions for terrorism risk were only regularly observed in countries, such as Great Britain, Northern Ireland, Israel, Spain, and South Africa, with a history of regional conflicts.

${ }^{23}$ The articles include Schmidt and Gerathewohl (1973) and Hübner (1981).

${ }^{24}$ Hartwig, 2002.

${ }^{25}$ See Michel-Kerjan and Pedell (2005) for a discussion on other terrorism insurance schemes.

${ }^{26}$ Terrorism insurance for policyholders with total insured values of less than 25 million are available through regular insurance contracts. 
is obtained from the fire insurance contract and the upper limit $(U L)$, which is selected by the policyholder. It should be noted that during the time period studied, Extremus did not adjust its premiums.

\section{Empirical analysis}

\section{The data}

The data set includes all contracts sold by the government-sponsored insurer from the company's foundation in the fourth quarter of 2002 through the first quarter of 2007. There are more than 1,000 observations per year in the data set. It provides detailed information on the policyholders and the policies purchased. It names the policyholder, his address, and the nature of the business. In addition, the data set contains the inception and expiration date of the policy, $M P L$, and $U L$. There are data on 5,614 terrorism insurance contracts. Considering renewals, we have 2,023 different insurance contracts. At the end of our observation period 1,036 contracts are still in force. The policyholders come from 18 industries. Most contracts (i.e., 2,424) are bought by real estate corporations. Many contracts are also bought by businesses from the financial sector. This is reflected by the fact that 513 contracts are purchased by banks, 665 by insurance companies, and 530 by real estate investment funds. Table 1 presents the number of policyholders by industry and year.

The data are highly skewed due to a small number of very large insurance contracts and a large number of smaller contracts. This skewness is reflected in the significant difference between the mean ( $€ 419$ million) and the median ( $€ 55$ million) of MPL. Consequently, Extremus' premium income depends greatly on its largest policyholders. The largest 10 contracts contribute to 19 per cent of total premium income. The largest 100 contracts ( 1.7 percentile) paid 66 per cent of the total premium the company collected. The mean (median) terrorism insurance premium is $€ 67,095(€ 11,201)$.

Comparing the numbers from our data set with the overall market-level data reported by the Association of German Insurers it becomes clear that terrorism insurance is not equally attractive for all of the 40,000 corporations in Germany that are eligible to purchase a separate terrorism insurance policy. Of these 40,000 corporations, only 2.9 per cent have decided that the benefits of a terrorism insurance policy outweigh its costs. The market penetration increases significantly with the size of the company: 21 per cent (2003) and 15 per cent (2004) of the 60 largest corporations ( $M P L>€ 5$ billion) purchase terrorism insurance. Table 2 provides the descriptive statistics with respect to the demand for terrorism insurance through Extremus. The table shows that 
Table 1 Policyholders by industry 2002-2007

\begin{tabular}{|c|c|c|c|c|c|c|}
\hline & $2002 / 3$ & 2004 & 2005 & 2006 & 2007 & $2002-2007$ \\
\hline Banks, Asset Managers & 99 & 111 & 106 & 105 & 92 & 513 \\
\hline Construction & 19 & 19 & 31 & 23 & 13 & 105 \\
\hline Utilities & 19 & 16 & 16 & 14 & 13 & 78 \\
\hline Airports & 26 & 22 & 20 & 22 & 17 & 107 \\
\hline Stores & 36 & 37 & 42 & 46 & 42 & 203 \\
\hline Real Estate & 490 & 452 & 460 & 530 & 492 & 2424 \\
\hline Real Estate Inv Funds & 96 & 100 & 107 & 120 & 107 & 530 \\
\hline Churches, Foundations & 21 & 20 & 19 & 21 & 17 & 98 \\
\hline Hospitals & 9 & 5 & 7 & 7 & 7 & 35 \\
\hline Art, Fairs & 12 & 10 & 11 & 10 & 9 & 52 \\
\hline Logistics & 11 & 15 & 14 & 15 & 12 & 67 \\
\hline Media, IT & 34 & 33 & 31 & 31 & 24 & 153 \\
\hline Other & 18 & 22 & 21 & 23 & 18 & 102 \\
\hline Local Authorities & 32 & 18 & 18 & 18 & 15 & 101 \\
\hline Tourism & 26 & 31 & 38 & 43 & 32 & 170 \\
\hline Heavy Industry & 28 & 31 & 36 & 35 & 23 & 153 \\
\hline Transportation & 10 & 11 & 12 & 11 & 12 & 56 \\
\hline Insurance & 194 & 118 & 127 & 121 & 105 & 665 \\
\hline Total & 1,180 & 1,072 & 1,117 & 1,195 & 1,050 & 5,614 \\
\hline
\end{tabular}

the mean relative amount of coverage purchased (quotient of $M P L$ and $U L$ ) is 86 per cent. A large part of the policyholders, 2,357 of 5,614, even purchase full insurance.

The low percentage of German firms purchasing terrorism insurance through Extremus poses questions. Unfortunately, there is no study readily available that compares the number of terrorism insurance policies sold through Extremus to the overall number of such policies sold in Germany. Yet, there exists evidence suggesting that Extremus captures a very large part of the total demand for terrorism insurance and that a very large part of the corporations eligible for purchasing terrorism insurance in Germany in fact has decided to self-insure. This assessment is supported by the replies to a small marketing campaign, aimed at large corporations, which Extremus conducted in $2003 / 4$. Using the answers to this campaign, we find that only a very small percentage of the firms, namely 15 per cent, had actually purchased terrorism coverage through other insurers. ${ }^{27}$ Among the firms purchasing terrorism

27 Twenty institutions responded to the marketing campaign conducted by Extremus. Nine of these were, at some point between 2002 and 2007, members of the German large cap DAX30 index. Of the 20 replies to this campaign there were only three firms indicating that they had purchased terrorism insurance through a different insurer. Four firms showed interest in buying 
The Geneva Risk and Insurance Review

66

Table 2 Descriptive statistics terrorism insurance contracts 2002-2007

\begin{tabular}{|c|c|c|c|c|c|c|c|}
\hline & & $2002 / 3$ & 2004 & 2005 & 2006 & 2007 & $2002-2007$ \\
\hline Degree of & Mean & 0.85 & 0.86 & 0.85 & 0.86 & 0.87 & 0.86 \\
\hline Coverage & Median & 1.00 & 1.00 & 1.00 & 1.00 & 1.00 & 1.00 \\
\hline Net premium & Mean & 89,014 & 73,207 & 59,934 & 57,151 & 56,220 & 67,095 \\
\hline$(€)$ & Median & 9,558 & 11,246 & 11,389 & 11,654 & 12,858 & 11,201 \\
\hline \multirow[t]{2}{*}{$\mathrm{MPL}^{\mathrm{a}}\left({ }^{\prime} 000 €\right)$} & Mean & 554,000 & 377,000 & 378,000 & 365,000 & 415,000 & 419,000 \\
\hline & Median & 48,300 & 54,200 & 55,800 & 586,000 & 61,100 & 55,000 \\
\hline \multirow[t]{2}{*}{$\mathrm{UL}^{\mathrm{a}}\left({ }^{\prime} 000 €\right)$} & Mean & 71,200 & 73,000 & 75,600 & 80,700 & 85,800 & 77,200 \\
\hline & Median & 43,300 & 46,400 & 47,600 & 50,000 & 50,300 & 47,800 \\
\hline
\end{tabular}

${ }^{a}$ Includes only contracts, where MPL Property, respectively, MPL Business Interruption $>0$.

MPL - maximum possible loss, UL - upper limit of compensation.

insurance through a competitor to Extremus are a bank, a construction company, and an industrial firm. In addition, the characteristics of the firms contained in the marketing campaign and which do not purchase terrorism insurance do not exhibit any systematic differences relative to the firms that have been buying terrorism insurance.

The regression analysis that the section "Regression analysis of aggregate demand" presents uses monthly data on the change in policies insured $\left(\Delta \mathrm{Pol}_{t}\right)$ and the change in premium income $\left(\Delta P \operatorname{Inc} c_{t}\right){ }^{28}$ The mean of $\Delta \mathrm{Pol}_{t}$ is equal to 3.97. Nevertheless, the mean of $\Delta P \operatorname{Inc}_{t}$ is negative $(€-38,682)$. The negative mean of $\Delta P I n c_{t}$ can be explained by the cancellation of some very large policies between May 2003 and March 2007. All contracts are due for renewal in January. We consequently observe the largest variation

terrorism insurance through Extremus. The reasons presented by the other 13 firms for not purchasing terrorism insurance ranged from assessments that the firms are not particularly at risk to doubts about the usefulness of purchasing a coverage against a specific risk in a single country. Among the four firms that wanted to purchase terrorism coverage through Extremus are a transportation firm, an asset manager, a firm that belongs to the category "heavy industry", and a very large bank (total assets > 100 billion). The mean of total assets (2004) of the three non-banks is 1.5 billion. There are three firms, among them one very large bank (total assets $>100$ billion), one firm from the transportation sector, and a construction firm that replied that they were purchasing terrorism insurance through a different supplier. The mean of total assets (2004) of the two non-banks is 4.3 billion. The mean of total assets of the firms that self-insure are 10.1 billion (data on total assets are not available for two firms). These firms belong to the following sectors: Transportation (2), Heavy Industry (8), Media, IT (2), and Utilities (1).

${ }^{28}$ Considering that Extremus was founded in November 2002 and that it took the insurer some time to establish its customer base, we only report our descriptive statistics from May 2003 onwards. Similarly, our regression analysis only uses data since May 2003. 
Table 3 Descriptive statistics

\begin{tabular}{lcccrr}
\hline Variable & Observations & Mean & Std. Dev & Min & Max \\
\hline$\Delta$ Pol $_{t}$ & 46 & 3.978261 & 37.8168 & -130 & 101 \\
$\Delta$ Pol $_{t} \mid t=$ January & 4 & -93.75 & 42.08226 & -130 & -48 \\
$\Delta$ Pol $_{t} \mid t \neq$ January & 42 & 13.28571 & 20.48234 & -39 & 101 \\
$\Delta$ Inc $_{t}$ & 46 & $-38,682.87$ & 599,721 & $-3,083,156$ & $1,792,691$ \\
$\Delta$ Inc $_{t} \mid t=$ January & 4 & $-1,289,924.00$ & $1,316,615$ & $-3,083,156$ & $-96,384$ \\
$\Delta$ Inc $_{t} \mid t \neq$ January & 42 & $80,482.99$ & 317,216 & 283,916 & $1,792,691$ \\
\hline
\end{tabular}

$\Delta$ Pol $_{t}-$ Change in the number of policies sold in period $t$ from period $t-1$.

$\Delta P$ Inc $_{t}-$ Change in premium income in period $t$ from period $t-1$.

during the month of January: $E\left(\Delta P\right.$ Inc $_{t} \mid t=$ January $)=€-1,289,924$ and $E\left(\Delta\right.$ Pol $_{t} \mid t=$ January $)=€-93.75$, respectively. Table 3 presents the descriptive statistics.

\section{Regression analysis of aggregate demand}

To test the learning hypothesis we limit our analysis to a time series approach of aggregate demand. The analysis focuses on large-scale terrorist attacks on the member states of the European Union. Such events have, so far, been rare. To reflect this fact and to accentuate that our study focuses on a risk that is new to corporate risk managers, we use the following selection criteria. We include large-scale terrorist events that occurred in member states of the European Union and which resulted in 50 or more casualties. In addition to this evidence and to highlight the particular relevance of terrorism risk in Germany, we also include the attempted attacks in Germany that might have led to a similar number of casualties. We searched the Global Terrorism Database $^{29}$ and confirmed the attempted attacks on German soil by consulting the annual report of the German Federal Office for the Protection of the Constitution. ${ }^{30}$ Our selection criteria provided us with the following events: the attacks on Madrid (11 March 2004), London (7 July 2005), and the attempt to bomb two trains in Germany (31 July 2006). We proceed as follows: first, accounting for the particularities of our data, we formulate our estimation equations. Second, we test whether recent terrorist activity has led to changes in the aggregate demand for terrorism insurance in Germany. Third, we examine how well our models predict the developments of the German insurance market by conducting a set of out-of-sample forecasts.

\footnotetext{
29 GTD, 2010.

${ }^{30}$ Verfassungsschutzbericht, 2006.
} 
68

We use monthly data on: (A) the change in the number of policies insured with Extremus, and (B) the change of premium income generated. The fact that the insurance contracts expire at the end of the calendar year results in 96.9 per cent of all contracts expiring in December. The same rule leads to a great number of contracts incepting in January ( 82.3 per cent). Nearly all contracts (97.7 per cent) sold in January end in December. Of the total net premium income of $€ 377$ million, 82 per cent was generated by contracts starting in January and 99 per cent can be attributed to contracts ending in December. Since contracts tend to be purchased for the whole year, we also see most of the change in premium income occurring in January.

Standard unit root tests (i.e., Dickey-Fuller) suggest that the two series are stationary at the standard significance levels. Further, our series do not appear to be serially dependent. ${ }^{31}$ In addition, we use robust standard errors in all estimations. We estimate two regression models:

$$
\begin{gathered}
\Delta \text { Pol }_{t}=\beta_{a 0}+\beta_{a 1} \text { January }+\sum_{i=1}^{3} \alpha_{a i} \text { Attack }_{i}+\sum_{i=1}^{3} \varphi_{a i} \text { Inter }_{i}+\varepsilon_{a}, \\
\Delta \text { Inc }_{t}=\beta_{b 0}+\beta_{b 1} \text { January }+\sum_{i=1}^{3} \alpha_{b i} \text { Attack }_{i}+\sum_{i=1}^{3} \varphi_{b i} \text { Inter }_{i}+\varepsilon_{b},
\end{gathered}
$$

where $i$ denotes the Madrid, London, and the attempted attacks on the German trains, respectively. The models explain the change in the number of policies $\left(\Delta \mathrm{Pol}_{t}\right)$ and the change in premium income $\left(\Delta P \operatorname{Inc} c_{t}\right)$ in a given month with the help of dummy variables denoting January (January), the months following an attack $\left(\right.$ Attack $\left._{i}\right)$, and interaction variables (Inter $\left.{ }_{i}\right)$. Assuming that it may take some time for corporations to revise their risk management strategies we set the $\operatorname{Attack}_{i}(i=1,2,3)$ variables equal to one for the month of the attack and the three months afterwards. ${ }^{32}$ The interaction variables (Inter ${ }_{i}$ ) are binary variables that are set to equal 1 for the January following the respective attack and zero otherwise. The interaction term thus captures the effect of a terrorist attack on the policyholders' tendency to renew their contracts following an attack. ${ }^{33}$

\footnotetext{
${ }^{31}$ Those results have not been reported to economize on space, but they are available upon request from the authors.

${ }^{32}$ We have also experimented with dummy variables for up to six months following an attack. However, none of the additional coefficients were significant and the results above did not change. A possible explanation has to do with the low variability in the number of contracts purchased and/or terminated throughout the year (see Table 6 for details).

${ }^{33}$ One may argue that the interaction terms capture a larger amount of year fixed-effects that may influence a firm's demand for insurance, in addition to the three terrorist events. In a separate
} 
Table 4 Ordinary least square estimates

\begin{tabular}{|c|c|c|}
\hline & Regression $A$ & Regression $B$ \\
\hline & $\Delta \mathrm{Pol}_{t}$ & $\Delta P$ Inc $_{t}(€$ thousands $)$ \\
\hline January & $\begin{array}{c}-144.65 * * * \\
(21.43)\end{array}$ & $\begin{array}{c}-3,181,946^{* * *} \\
(332,573)\end{array}$ \\
\hline Attack $_{1}$ & $\begin{array}{l}-5.66 \\
(11.19)\end{array}$ & $\begin{array}{c}-95,672 \\
(173,681)\end{array}$ \\
\hline Attack $_{2}$ & $\begin{array}{l}-7.99 \\
(12.74)\end{array}$ & $\begin{array}{c}-85,429 \\
(197,744)\end{array}$ \\
\hline Attack $_{3}$ & $\begin{array}{l}-3.66 \\
(12.74)\end{array}$ & $\begin{array}{c}-43,305 \\
(197,744)\end{array}$ \\
\hline Inter $_{1}$ & $\begin{array}{l}62.00^{* *} \\
(29.84)\end{array}$ & $\begin{array}{c}1,656,964 * * * \\
(463,1480)\end{array}$ \\
\hline Inter $_{2}$ & $\begin{array}{l}82.00 * * * \\
(29.84)\end{array}$ & $\begin{array}{c}2,986,772 * * * \\
(463,148)\end{array}$ \\
\hline $\mathrm{Inter}_{3}$ & $\begin{array}{c}1.00 \\
(29.84)\end{array}$ & $\begin{array}{c}2,529,191 * * * \\
(463,148)\end{array}$ \\
\hline Cons. & $\begin{array}{l}14.66^{* * * *} \\
(3.73)\end{array}$ & $\begin{array}{l}98,790^{*} \\
(57,894)\end{array}$ \\
\hline$N$ & 46 & 46 \\
\hline$R^{2}$ & 0.74 & 0.75 \\
\hline
\end{tabular}

Robust standard errors in parentheses.

$\Delta \mathrm{Pol}_{t}$ denotes the change in the number of policies sold in period $t$ from period $t-1 ; \Delta P$ Inc $_{t}$ denotes the change in premium income in period $t$ from period $t-1$; Attack $_{1}$ denotes the Madrid attacks; Attack $_{2}$ denotes the London attacks; Attack $_{3}$ denotes the attempted attacks in Germany; Inter $_{1}$ denotes the January following the Madrid attacks; Inter 2 denotes the January following the London attacks; Inter $_{3}$ denotes the January following the attempted attacks in Germany.

*Significant at 10 per cent; **significant at 5 per cent; ***significant at 1 per cent.

If the estimation shows that both coefficient vectors $\alpha_{i}^{\prime} s$ and $\varphi_{i}^{\prime} s$ are not significantly different from zero we must conclude that the data do not support the learning hypothesis described above. Finding that the attack variables are significant and positive, we would conclude that terrorist attacks lead to a shock in demand. Finding positive coefficients for the interaction variables would imply that terrorist attacks have a significant effect on the demand for insurance of Extremus' customers.

Table 4 reports the estimation results. The results indicate that in the first months following an attack there is no significant change in the demand for

analysis (not reported but available upon request), we have also experimented with year fixedeffects that switched to 1 for the years after each attack. Nevertheless, none of the new dummy variables appeared significant. 
terrorism insurance from previously uninsured corporations. The dummy variables $\left(\right.$ Attack $\left._{i}, i=1,2,3\right)$ are not significant. Thus, following an attack previously uninsured corporations do not immediately revise their risk assessment. Nevertheless, we do find that the terrorist attacks have a significant influence on the demand for terrorism insurance. The coefficients of two (three) of the three (three) interaction action terms in Regression A (Regression B) are significant and greater than zero. Only the coefficient estimate for Inter ${ }_{3}$, denoting the effect of the attempted train bombings in Germany on $\Delta$ Pol $_{t}$ in Regression A is not significant.

The estimates provide support for the learning hypothesis. Terrorists' activity level observed during the previous 12 months has a strong impact on corporate insurance decisions in Germany. Owing to these attacks, the aggregate demand for terrorism insurance through Extremus did not decline as expected during January in years 2005, 2006, and 2007, respectively, but proved to be rather stable. Thus, due to the Madrid and London attacks demand for terrorism insurance has increased on both occasions (see also Table 6). The negative coefficient for the January variable (-144 for Regression A and - 3.18 million for Regression B) captures the overall drop in the demand for terrorism insurance that resulted from the absence of major terrorist attacks on Western European targets between the foundation of the terrorism insurer in November 2002 and January 2004.

To better understand the data, we further investigate whether corporations react differently across different location and sector groupings, respectively. Specifically, we first divide our data into two groups: subgroup (a) (Small Cities) includes corporations with headquarters located in cities with less than 500,000 inhabitants, while subgroup (b) (Large Cities) concerns those from larger cities. We estimate two multivariate regression models (where in each equation the dependent variable is the change in the number of policies sold) to gain insights into the differences between these groups.

Regressions C confirms the prior finding that the Madrid and London terrorist events had a positive impact on the demand for terrorism insurance. While the attempted attacks in Germany do not appear to significantly alter the demand of the firms in larger cities, they do appear to have lead to an actual decrease in the demand of the firms in smaller cities. In addition, Table 5 shows that corporations in larger cities purchased more insurance in response to the three attacks than corporations located in smaller cities. While overall, according to the Breusch-Pagan test of independence, the two models do not appear statistically independent, the individual interaction coefficients are significantly different from each other across the two subgroups at the 10 per cent and 5 per cent significance level, respectively. In addition, Regression D in Table 5 investigates whether corporations responded differently to the terrorist attacks according to their sector (financial vs. 
Table 5 Multivariate ordinary least squares by sector and size

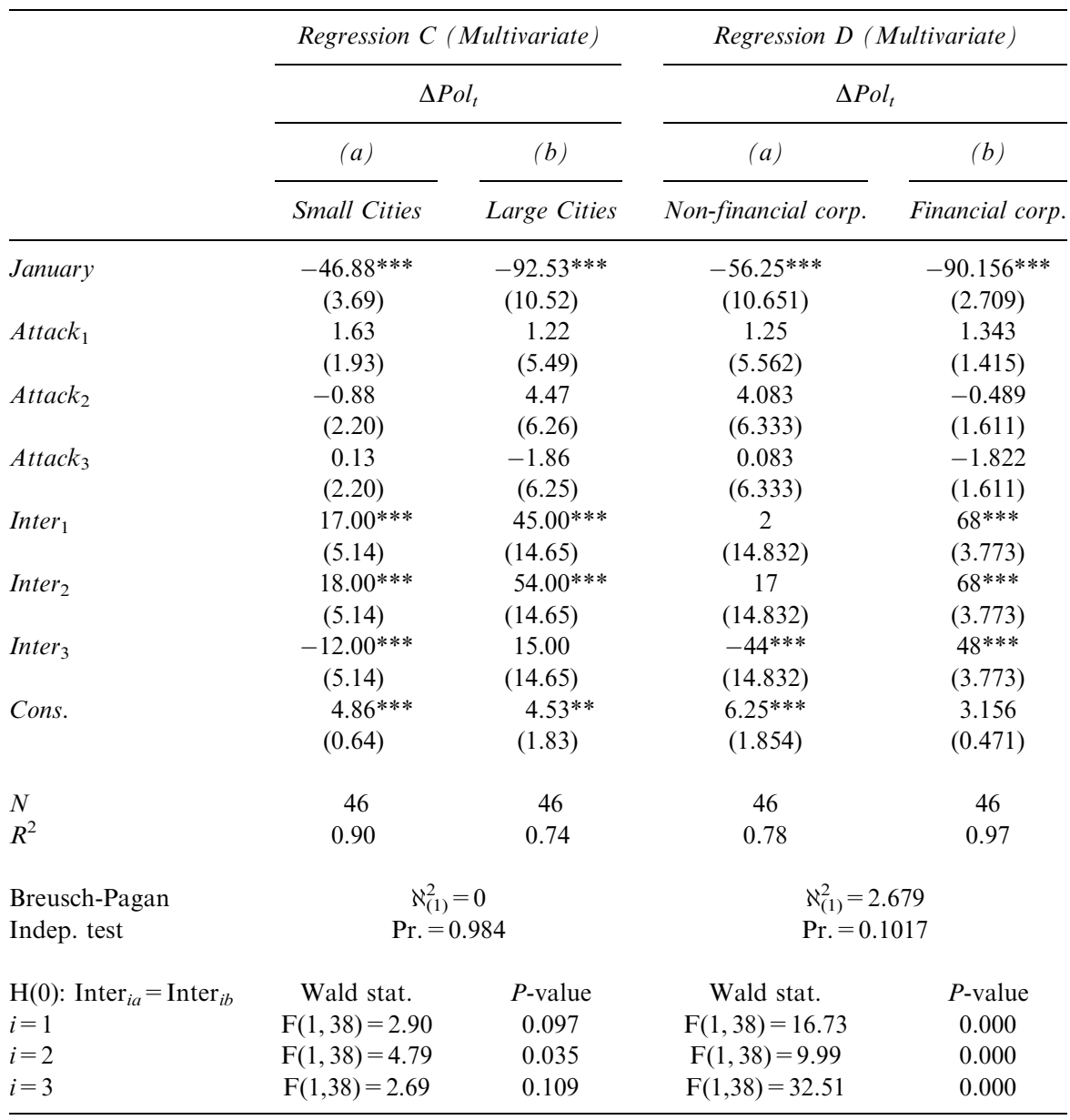

Robust standard errors in parentheses.

Large Cities include all cities in Germany with more than 500,000 inhabitants. Small Cities include the rest. Financial corporations are defined as Asset Management Corporations, Banks, Insurers, and Real Estate Investment Funds. Non-Financial corporations comprise all other corporations. $\Delta$ Pol $_{t}$ denotes the change in the number of policies sold in period $t$ from period $t-1 ;$ Attack $_{1}$ denotes the Madrid attacks; Attack $_{2}$ denotes the London attacks; Attack $_{3}$ denotes the attempted attacks in Germany; Inter ${ }_{1}$ denotes the January following the Madrid attacks; Inter 2 denotes the January following the London attacks; Inter 3 denotes the January following the attempted attacks in Germany.

*Significant at 10 per cent; ${ }^{* *}$ significant at 5 per cent; ***significant at 1 per cent. 
Table 6 Net change (new contracts minus cancelled contracts) for December/January

\begin{tabular}{|c|c|c|c|c|c|}
\hline Month & 2003 & 2004 & 2005 & 2006 & 2007 \\
\hline January & & 177 & 142 & 88 & 63 \\
\hline December & -258 & -198 & -131 & -182 & \\
\hline Net policies & & & & & \\
\hline Dec/03-Jan/04 & -81 & & & & \\
\hline $\mathrm{Dec} / 04-\mathrm{Jan} / 05$ & -56 & & & & \\
\hline $\mathrm{Dec} / 05-\mathrm{Jan} / 06$ & -43 & & & & \\
\hline Dec/06-Jan/07 & -119 & & & & \\
\hline
\end{tabular}

non-financial). ${ }^{34}$ Thus, results in Table 5 show that in response to all of the terrorist attacks considered (including the one in Germany), financial corporations demanded more insurance. The impact was greater for the financial corporations than for the non-financial ones. Further, the interaction terms appear significantly different from each other across the two subgroups at the 5 per cent significance level. This evidence suggests that corporations in larger cities and financial corporations learned more from the attacks than firms in smaller cities and nonfinancial corporations, respectively.

To further investigate the data, we also perform a separate analysis on the firms with coverage prior to the three terrorist events and on the firms that began purchasing insurance after each event, respectively. First, Table 6 shows the net change in the number of contracts computed as the difference between the number of previously uninsured corporations that enter into new contracts and the number of contracts that are being cancelled for each December/January. As explained above, most of the changes occur in December (net loss in the number of new contracts) and January (net gain). Overall, the loss experienced in December is higher than the net gain in the following January, such that following each consecutive December/January the number of contracts in place is lower than before. Yet, Table 6 shows that following the terrorist events in Madrid and London the number of contracts did not decline as expected. Thus, while following December 2003-January 2004 we experienced a net loss of 81 contracts, the loss was smaller for the December 2004-January 2005 and December 2005-January 2006 periods at 56 and 43 contracts, respectively. In turn, the lack of major terrorist events in 2006 (similar in scale to those in Madrid and London) appears to have lead

\footnotetext{
${ }^{34}$ Financial corporations are defined as Asset Management Corporations, Banks, Insurers, and Real Estate Investment Funds. Non-financial corporations comprise all other corporations.
} 
Table 7 Separate regressions using only contracts purchased prior to each attack

\begin{tabular}{|c|c|c|c|c|c|c|}
\hline \multirow[t]{2}{*}{ Variable } & \multicolumn{2}{|c|}{ Prior Madrid } & \multicolumn{2}{|c|}{ Prior London } & \multicolumn{2}{|c|}{ Prior train attacks } \\
\hline & Coefficient & Std. Error & Coefficient & Std. Error & Coefficient & Std. Error \\
\hline January & $-91.469^{* * *}$ & (7.909) & $-93.875^{* * *}$ & (8.604) & $-97.125^{* * *}$ & $(7.868)$ \\
\hline Attack $_{1}$ & -0.969 & (4.130) & 5.875 & $(4.493)$ & 2.625 & (4.109) \\
\hline Attack $_{2}$ & -1.469 & $(4.703)$ & 0.458 & $(5.116)$ & 3.208 & (4.678) \\
\hline Attack $_{3}$ & -1.469 & $(4.703)$ & -4.542 & $(5.116)$ & -4.125 & $(4.678)$ \\
\hline Inter $_{1}$ & $-110.000^{* * *}$ & (11.014) & $29.000 * *$ & (11.982) & $29.000 * *$ & $(10.957)$ \\
\hline Inter $_{2}$ & -1.000 & (11.014) & $-39.000 * * *$ & $(11.982)$ & $46.000^{* * *}$ & $(10.957)$ \\
\hline Inter $_{3}$ & 0.001 & (11.014) & $-47.000^{* * *}$ & (11.982) & $-98.000 * * *$ & $(10.957)$ \\
\hline Intercept & 1.469 & $(1.377)$ & $3.875^{* *}$ & $(1.498)$ & $7.125^{* * *}$ & $(1.370)$ \\
\hline$N$ & \multicolumn{2}{|c|}{46} & \multicolumn{2}{|c|}{46} & \multicolumn{2}{|c|}{46} \\
\hline$R^{2}$ & \multicolumn{2}{|c|}{0.96} & \multicolumn{2}{|c|}{0.95} & \multicolumn{2}{|c|}{0.96} \\
\hline$F_{(7,38)}$ & \multicolumn{2}{|c|}{142.91} & \multicolumn{2}{|c|}{93.28} & \multicolumn{2}{|c|}{122.16} \\
\hline
\end{tabular}

This table considers only contracts in place prior to each event. Attack $_{1}$ denotes the Madrid attacks; Attack $_{2}$ denotes the London attacks; Attack $_{3}$ denotes the attempted attacks in Germany; Inter 1 denotes the January following the Madrid attacks; Inter ${ }_{2}$ denotes the January following the London attacks; Inter 3 denotes the January following the attempted attacks in Germany.

*Significant at 10 per cent; ${ }^{* *}$ significant at 5 per cent; ${ }^{* * *}$ significant at 1 per cent.

to an increase in the rate of cancelled contracts. Thus, 119 contracts were lost following the December 2006-January 2007 period. Overall, Table 6 provides some support for the findings in Table 4 and for the learning hypothesis. Yet, Table 6 also shows that the interaction between the terrorist attacks, companies entering new contracts, companies cancelling their contracts, and a general tendency of companies to cancel their contracts is complex.

Table 7 adds to the previous results by showing that the increase in the demand for terrorism insurance is mainly driven by companies that were previously uninsured. Table 7 considers only those corporations that were previously insured and shows the OLS results of re-estimating Regression A in Table 4 for companies that had purchased insurance prior to the Madrid, London, and Germany train incidents, respectively. Columns 2 and 3 report the regression coefficients and the corresponding standard errors using only observations on the firms that had insurance prior to the Madrid attacks. The coefficient on Inter $_{1}$ is negative and highly significant. This result shows that in spite of the Madrid attacks a significant number of corporations did not renew their contracts. Nevertheless, a separate regression on the companies that were insured prior to the London attacks shows that Inter $_{1}$ is now positive and highly significant. This outcome (i.e., in columns 4 and 5) combined with the one in columns 2 and 3 highlights that the increase in demand for terrorism 
The Geneva Risk and Insurance Review

74

Table 8 Out-of-sample predictions for Regressions A and B

\begin{tabular}{|c|c|c|c|c|c|c|c|c|}
\hline \multirow[t]{2}{*}{ Month } & \multicolumn{4}{|c|}{$\Delta P o l$} & \multicolumn{4}{|c|}{$\Delta P \operatorname{Inc}_{t}$} \\
\hline & Prediction & Actual & $t$-stat & $P$-value & Prediction & Actual & $t$-stat & $P$-value \\
\hline $11 / 2006$ & $\begin{array}{c}16 \\
(4.24)\end{array}$ & 4 & 2.73 & 0.01 & $\begin{array}{c}112,130 \\
(660,040)\end{array}$ & $-21,631$ & 2.03 & 0.05 \\
\hline $12 / 2006$ & $\begin{array}{c}16 \\
(4.24)\end{array}$ & 13 & 0.70 & 0.49 & $\begin{array}{c}112,130 \\
(660,040)\end{array}$ & 39,475 & 1.10 & 0.28 \\
\hline $1 / 2007$ & $\begin{array}{c}-130 \\
(22.44)\end{array}$ & -129 & -0.05 & 0.96 & $\begin{array}{c}-3,083,156 \\
(349,450)\end{array}$ & $-553,966$ & -7.24 & 0.00 \\
\hline $2 / 2007$ & $\begin{array}{c}16 \\
(4.24)\end{array}$ & 14 & 0.37 & 0.71 & $\begin{array}{c}112,130 \\
(660,040)\end{array}$ & $-4,953$ & 1.77 & 0.09 \\
\hline $3 / 2007$ & $\begin{array}{c}16 \\
(4.24)\end{array}$ & 2 & 3.20 & 0.00 & $\begin{array}{c}112,130 \\
(660,040)\end{array}$ & 8,759 & 1.57 & 0.13 \\
\hline
\end{tabular}

insurance following the Madrid attacks appears to be mainly due to new clients. Similarly, the OLS results in columns 6 and 7, where we use information only on companies with contracts in place prior to the attempted attacks on the trains in Germany, show that the increase in the demand for terrorism insurance following the London attacks is mainly due to previously uninsured corporations. ${ }^{35}$

Finally, in order to check the robustness of our model, Table 8 reports the out-of-sample forecasting performance of the models from Eqs. (A) and (B). We trim the last 10 per cent of the observations from the sample (i.e., roughly five observations) and re-estimate the equations on the shorter sample. Using the newly estimated coefficients, we obtain predictions of the previously trimmed data. For equation (A), three of the actual observations fall within the 95 per cent confidence interval formed around the forecasts. For equation (B), the number of observations predicted correctly with 95 per cent confidence increases to four. This evidence suggests that our models have out-of-sample predictive power and thus confirms their validity.

\section{Duration analysis}

Our confidence hypothesis suggests that a firm does not only learn about its risk over time, but that it also gets more confident in its judgement. If firms

\footnotetext{
${ }^{35}$ Note that coefficient on Inter $_{2}$ is negative in column 4 of Table 7 but positive in column 6 of the same table. This result is explained by the new companies that decided to buy terrorism insurance following the London attacks.
} 
get more confident in their risk assessment over time, we can express the prospective reference theory's posterior probability $p^{*}$ as a function of $t$ :

$$
p_{t}^{*}=\frac{\vartheta_{0} q_{0}+\vartheta_{1} q_{1}+\vartheta_{2} q_{2}+\cdots+\vartheta_{t-1} q_{t-1}+p_{t} \xi}{\vartheta_{0}+\vartheta_{1}+\vartheta_{1}+\cdots+\vartheta_{t-1}+\xi},
$$

where $\vartheta_{i}^{\prime} s$ mark the weighing factors of the initial prior (i.e., $\vartheta_{0}$ ) and the weighing factors of the $t-1$ periods thereafter. If firms grow more confident in their judgement, and assuming that $i$ is constant for $i>0$, we would expect that the weight of new information $\xi / \sum_{i=0}^{t-1} \vartheta_{i}$ decreases in $t$. Since our data have a time dimension and since policies incept at different points in time, we are actually able to test if corporations grow more confident in their risk management decisions the longer they have been insured. To do this we set $t$ equal to the time that the firm $j$ has been insured against terrorism. Assuming that policyholders drop their policies once costs exceed benefits, we can infer about $p_{j t}^{*}$ from the probability that firm $j$ in period $t$ decides that the costs of a terrorism policy exceed its benefits. Speaking in terms of a duration model, we infer about how $p_{j t}^{*}$ changes over time from the slope of the hazard rate $\lambda(t)$ :

$$
\lambda_{j}(t)=P_{j}\left(\operatorname{costs}_{t}>\text { benefits }_{t} \mid \operatorname{costs}_{t-a} \leqslant \text { benefits }_{t-a}\right) \text {, where } a<t<0 \text {. }
$$

As Extremus kept prices constant, we do not have to control for the costs of terrorism insurance. Instead, it is sufficient for us to focus on the probability

a

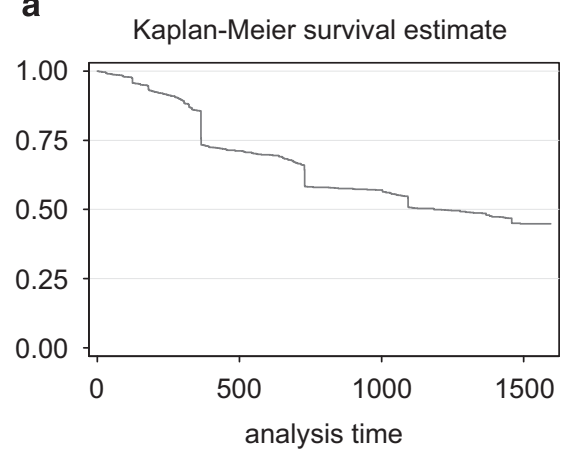

b

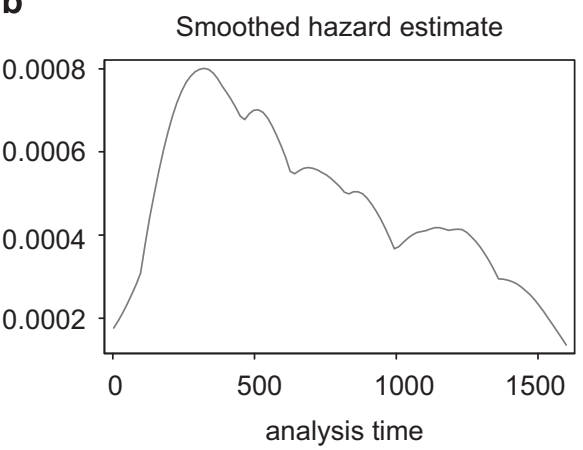

Figure 1. (a) Kaplan-Meier survival estimate; (b) smoothed hazard estimate. 
that the perceived exposure of a terrorist attack $p_{j t}^{*}$ falls under the threshold that makes the purchase of terrorism insurance beneficial. Finding that the slope of the hazard rate, $\lambda^{\prime}(t)$, is negative (positive) would imply that the policyholders grow more confident (less confident) in their risk management decisions over time and that consequently $\sum_{i=0}^{t-1} \vartheta_{i} / \xi$ increases over time.

We follow the suggestions of Kalbfleisch and Prentice ${ }^{36}$ to investigate the slope of the hazard function using a parametric duration model. Figures $1 \mathrm{a}$ and $\mathrm{b}$ graph the survival table and hazard rate using non-parametric methods, respectively.

The survival graph reflects the fact that we do not have any information on the cancellations of the policyholders purchasing terrorism insurance past 31 March 2007. The non-parametric estimate of the hazard function indicates that the probability of cancelling the terrorism insurance policy first increases before it eventually decreases. This non-monotonic behaviour of the hazard function leads us to fit both a log-logistic and a log-normal duration model to the data. ${ }^{37}$ Both models are highly significant: the likelihood ratio test statistics of the joint restrictions are significant at the 0.1 per cent level. The loglikelihood of the log-logistic (log-normal) model is -2350 (-2351). Yet, the Akaike Information Criterion (AIC) indicates that the log-logistic model $(\mathrm{AIC}=4749.44)$ fits the data somewhat better than the log-normal specification $(\mathrm{AIC}=4751.54) .{ }^{38} \mathrm{We}$ consequently proceed with the log-logistic model. The log-logistic hazard function can be expressed as:

$$
\lambda_{j}(t)=\frac{\left(\exp \left(-x_{j} \beta\right)\right)^{1 / \gamma} t^{1 /(\gamma-1)}}{\gamma\left(1+\exp \left(-x_{j} \beta\right)\right)^{1 / \gamma} t^{1 / \gamma}}
$$

where $x_{j}$ marks the vector of constant covariates of subject $j, \gamma$ is the scale parameter that is estimated from the data, and $\beta$ are the fitted coefficients.

We use a number of different time-invariant covariates as we expect that both a firm's exposure to terrorism risk and other characteristics influence its decision to stay insured against terrorism. Our covariates control for the policyholder's sector (dindustry ${ }_{k}$ ), the policyholder's size $(\log (U L))$, for corporations purchasing full insurance (dfull_insurance), and for companies located in large cites (dlarge_city). Further, we control for firms where the policyholder's headquarters are outside of Germany (dforeign). We

\footnotetext{
36 Kalbfleisch and Prentice (1980).

${ }^{37}$ See Kalbfleisch and Prentice (1980, pp. 21-38).

38 The AIC of duration models using Weibull, exponentially, and Gompertz distributed error terms are $4828.33,4826.60$, and 4788.29 , respectively.
} 
Table 9 Log-logistic regression - accelerated failure-time form

\begin{tabular}{|c|c|c|}
\hline Variable & Coefficient & Std. Errol \\
\hline \multicolumn{3}{|l|}{ Equation 1:_t } \\
\hline dforeign & -0.067 & $(0.277)$ \\
\hline DLargeCity & $-0.303 * * *$ & $(0.074)$ \\
\hline d_before_2004 & $-0.384 * * *$ & $(0.074)$ \\
\hline $\ln (U L)$ & $0.363 * * *$ & $(0.050)$ \\
\hline dfull_insurance & -0.126 & $(0.085)$ \\
\hline Construction & -0.290 & $(0.234)$ \\
\hline Utilities & 0.511 & $(0.340)$ \\
\hline Airports & 0.183 & $(0.288)$ \\
\hline Stores & 0.318 & $(0.214)$ \\
\hline Real Estate & $0.374 * * *$ & $(0.118)$ \\
\hline Real Estate Inv Funds & $0.590 * * *$ & $(0.161)$ \\
\hline Churches & $0.859 * * *$ & $(0.306)$ \\
\hline Hospital & 0.043 & $(0.346)$ \\
\hline Art, Fairs & 0.473 & $(0.402)$ \\
\hline Logistics & $0.598^{*}$ & $(0.340)$ \\
\hline Media, IT & 0.295 & $(0.229)$ \\
\hline Other & 0.016 & $(0.267)$ \\
\hline Local Authorities & -0.130 & $(0.218)$ \\
\hline Tourism & $0.674 * * *$ & $(0.235)$ \\
\hline Heavy Industry & -0.209 & $(0.210)$ \\
\hline Transportation & $0.673^{*}$ & $(0.402)$ \\
\hline Insurance & 0.079 & $(0.134)$ \\
\hline Intercept & 0.932 & $(0.874)$ \\
\hline \multicolumn{3}{|l|}{ Equation 2: In_gam } \\
\hline Intercept & $-0.252 * * *$ & $(0.027)$ \\
\hline$N$ & \multicolumn{2}{|c|}{2023} \\
\hline Log-likelihood & \multirow{2}{*}{\multicolumn{2}{|c|}{$\begin{array}{r}-2350.723 \\
147.306\end{array}$}} \\
\hline$\chi_{(22)}^{2}$ & & \\
\hline
\end{tabular}

In addition to the indicator variables that capture the industry in which a policyholder belongs we employ the following time-invariant covariates: $d$ foreign is 1 if the policyholder's headquarters are outside of Germany; dLargeCity is 1 for firms in large cities; d_before_2004 is 1 if the firm purchased insurance in 2002 and/or 2003; $\ln (U L)$ is the log of the upper limit of compensation; dfull_insurance is 1 for the policyholders purchasing full insurance.

*Significant at 10 per cent; ${ }^{* * *}$ significant at 1 per cent.

also control for differences in the demand for terrorism insurance during the years 2002 and 2003, where the latter was the first full year that Extremus provided coverage. To do this, we use a dummy variable identifying all policyholders that purchased terrorism insurance already before 2004 (d_before_2004). 
Column 1 in Table 9 presents the coefficient estimates and the estimated scaling parameter.

We find that the expected time a company stays in our sample is significantly shorter if it purchased terrorism insurance before 2004. In addition, companies located in larger cities have a greater tendency to leave the sample. Policyholder's size on the other hand seems to have a positive effect on the time that the firm stays insured with Extremus. We also find evidence that firms from the Real Estate Sector and Religious institutions tend to stay insured for a longer time. The coefficient estimate for firms with headquarters outside of Germany (dforeign) is not significant. Interestingly, firms that purchased full terrorism coverage are not more likely to stay insured.

The positive influence of a policyholder's size $(\log (U L))$ on the propensity to stay insured is not entirely unexpected. Indeed, terrorists have a tendency to attack better known targets. ${ }^{39}$ This finding is also in line with the results of Michel-Kerjan et al. ${ }^{40}$ who find that larger companies in the United States are more likely to purchase terrorism insurance. However, the finding that firms located in larger cities have a lower propensity to stay insured comes as a surprise. Here, one would expect that the greater density of targets available in a larger city contributed to an increased exposure. To ensure that the finding is not possibly due to the presence of multicollinearity, we exclude (a) $\log (U L)$ and (b) dlarge_city from our duration model. ${ }^{41}$ Yet, the coefficient estimates of d_large_city in estimation (a) or $\log (U L)$ in estimation (b) are largely unchanged and significant. Thereafter, we break our sample into two subsamples. The first sub-sample consists of policyholders that started to buy terrorism insurance in 2002 or 2003. The second sub-sample consists of those that started in 2004 or later. ${ }^{41}$ Here, we find that the coefficient for $d$ large_city is only significant and negative for the first sub-sample. The coefficient for $\log (U L)$ remains positive and significant for both sub-samples. Thus, it is primarily firms located in larger cities which purchased terrorism insurance already in 2002 or 2003 that were quicker to decide that the costs of terrorism insurance exceeded its benefits.

The concave shape of the hazard function ${ }^{42}$ and the highly significant scaling parameter $\gamma$ of 0.77 provide support for the confidence hypothesis. First, the hazard rate increases and peaks after about 1 year. Thus, up to 1 year after purchasing the policy firms are increasingly willing to reverse their risk management decisions. After this point, firms are less willing to change their

\footnotetext{
${ }^{39}$ Keohane and Zeckhauser, 2003

${ }^{40}$ Michel-Kerjan et al. (2010).

41 The results are available upon request.

42 Not reported, but available upon request.
} 
risk management decisions. This finding indicates that firms grow more confident in their risk management decisions over time.

We test the robustness of our findings fitting a log-normal ${ }^{43}$ duration model that according to the AIC has the second best fit to the full sample. Here, we again find that the slope of the hazard function is negative for $t>1$ year. Since we are concerned that the negative slope of the duration model might be due to the greater tendency of early adopters to drop their terrorism insurance policies we split our sample into two parts: we fit separate log-logistic, lognormal, exponential, Weibull and Gompertz duration models to (a) all policyholders that start purchasing insurance before 2004 and (b) after 2004. The robustness checks support our prior findings. For (a) we find that the AIC indicates that the log-normal duration model fits best. For (b) it is the loglogistic model that fits best. The scaling coefficients of the log-logistic model are (a) $\gamma=0.76$ and (b) also $\gamma=0.78$. The scaling coefficients for the log-normal model are (b) $\sigma=1.44$ and (b) $\sigma=1.31 .{ }^{44}$ In addition, we also estimated a semiparametric Cox proportional hazard model that strengthens the results above. $^{45}$ The additional models thus provide further support for the negative slope of the hazard estimates when $t>1$ year.

The estimation results provide strong support for the confidence hypothesis. A firm's propensity to drop its terrorism insurance policy decreases when the contract has been renewed once. Given that most firms decide to renew/end the insurance contract on an annual basis, it is clear that if firms are to make changes to their contracts, they do so around the time when the contract is supposed to expire (e.g., no early termination). After the contract has been renewed at least once, it seems that the failure rate (i.e., probability to terminate the contract) decreases. This decreasing tendency to reverse past risk management decisions provides support for our confidence hypothesis. The longer the firm has been in our sample, the less it is willing to reverse its risk management decisions.

Since policies incept at different points in time and due to the robustness of our results for our subsamples and alternative regression models, we are confident that the negative slope of the hazard function is due to the decreasing weight that corporations attribute to new information on terrorism risk. Thus, although corporations learn from new events their confidence in their risk management decisions increases over time.

\footnotetext{
43 The AIC indicate that this is the second best model.

44 All scaling parameters are significant at the 1 per cent level.

${ }^{45}$ In particular the model supports the non-monotonic shape of the hazard function. The results from these tests are available upon request.
} 


\section{Conclusion}

In this paper we study corporations' management of a highly dynamic risk, namely terrorism risk. Considering both the literature on corporate risk management and individual decision-making, we propose some theoretical considerations of how corporations process new information on a highly dynamic risk. We consequently apply a concept developed for individual decision-making to a corporate context. This concept, called prospective reference theory, allows subjects and individuals to update their probability assessment based upon recent observations. We argue that corporations' risk management decisions for terrorism risk are governed by a process that permits for a dynamic updating of probabilities. Looking at the aggregate demand for terrorism insurance through the government-based insurer and following three major terrorist events in Europe after 9-11, we find that corporations learn from single events and that they adjust their full-year risk management decisions accordingly. Specifically, while results in the paper show that there is a general tendency that companies cancel their contract (which is especially true for the companies that purchased insurance initially in 2002 and 2003), additional evidence shows that as a result of the new terrorist events, previously uninsured corporations enter new terrorism insurance contracts in the month of January following each event. Results in the paper show that financial, larger corporations, and corporations in larger cities purchase more terrorism insurance in response to terrorist incidents than non-financial or smaller corporations, and those in smaller cities, respectively. This evidence supports our learning hypothesis that recent terrorist activity has a strong influence on the demand for terrorism insurance.

Further, a duration analysis at the firm level suggests that the probability of a firm to cancel its policy declines over time. More precisely, as firms do not have the tendency to immediately reverse their risk management decisions, the probability of cancelling their policies starts declining after a firm has been insured with Extremus for a year. Thus, it appears that the weight between prior information and new information changes. The evidence suggests that firms tend to grow more confident in their risk management decisions and that the value that they assign to new information declines over time. This result supports our confidence hypothesis.

\section{Acknowledgements}

The authors thank Achim Wambach, the editor, and two anonymous referees. In addition, the authors thank Thomas Berry-Stoelzle, Walter Enders, Oliver Fabel, Bruno Gas, Andre Liebenberg, Kathleen McCullough, and Harris Schlesinger and the participants of the 2007 meeting of the American Risk and Insurance Association, the annual conference of the German Association of 
Insurance Sciences 2007, the 2008 annual meeting of the Financial Management Association, the 2008 meeting of the German Economic Association and the participants of the seminars at the University of Mississippi, University of Georgia, and University of Alabama. Christian Thomann acknowledges financial support from the Deutscher Verein für Versicherungswissenschaft. All errors and omissions are our own. The views expressed in this paper and all remaining errors are solely the responsibility of the authors.

\section{References}

Aunon-Nerin, D. and Ehling, P. (2008) 'Why firms purchase property insurance', Journal of Financial Economics 90: 298-312.

Cole, C.R. and McCullough, K.A. (2006) 'A reexamination of the corporate demand for reinsurance', Journal of Risk and Insurance 73: 169-192.

Enders, W. and Sandler, T. (2000) 'Is transnational terrorism becoming more threatening? A time series investigation', The Journal of Conflict Resolution 44: 307-332.

Enders, W. and Sandler, T. (2006) The Political Economy of Terrorism, Cambridge: Cambridge University Press.

Extremus (2003) 'Geschäftsbericht 2002, Extremus Versicherungs-Aktiengesellschaft', Köln, http:// www.extremus.de/unternehmen_geschaeftsbericht.phtml, accessed 04 April 2011.

Fuerst, F. (2005) 'Exogenous shocks and real estate rental markets: An event study of the 9/11 attacks and their impact on the New York office market', in H. Chernick (ed) Resilient City, New York: Russell Sage Foundation Publications.

GTD. (2010) 'Global Terrorism Database', from http://www.start.umd.edu/gtd/, accessed 30 June 2010.

Harless, D. (1993) 'Experimental tests for prospective reference theory', Economics Letters 43: 71-76.

Hartwig, R. (2002) 11 September 2001: One hundred minutes of terror that changed the global insurance industry forever. in Geneva Association (ed) Etudes et Dossiers No. 251. Geneva, Special Issue on the Economic Consequences of the September 11 Attacks on National Insurance Markets.

Hoffman, B. (1997) 'The confluence of international and domestic terrorism', Terrorism and Political Violence 9: 1-15.

Hoyt, R. and Khang, H. (2000) 'On the demand for corporate property insurance', Journal of Risk and Insurance 67: 91-107.

Hübner, U. (1981) 'Rechtsprobleme bei der Deckung politischer Risiken', Zeitschrift für die gesamte Versicherungswirtschaft 70: 1-48.

Jakus, P. and Shaw, D. (2003) 'Perceived hazard and product choice: An application to recreational site choice', Journal of Risk and Uncertainty 26: 77-92.

Kalbfleisch, J. and Prentice, R. (1980) The Statistical Analysis of Failure Time Data, New York, Chichester, Brisbane, Toronto: Wiley.

Keohane, N. and Zeckhauser, R.J. (2003) 'The ecology of terror defense', Journal of Risk and Uncertainty 26: 201-229.

Kunreuther, H., Michel-Kerjan, E. and Porter, B. (2003) Assessing, managing and financing extreme events: Dealing with terrorism, working paper, Vol. 10179, National Bureau of Economic Research, Cambridge.

MacMinn, R. and Garven, J. (1999) 'On corporate insurance', in D. Georges (ed) Handbook of Insurance, Boston: Kluwer, pp. 541-564.

Michel-Kerjan, E. and Pedell, B. (2005) 'Terrorism risk coverage in the post-9/11 era: A comparison of new public-private partnerships in France, Germany and the U.S.', Geneva Papers on Risk and Insurance - Issues and Practice 30: 144-170. 
Michel-Kerjan, E., Raschky, P. and Kunreuther, H. (2010) 'Corporate demand for insurance: An empirical analysis of the U.S. market for catastrophe and non-catastrophe risks', Paper presented at the Annual Meeting of the American Economic Association, American Economic Association.

National Obituary Archive-Honor Roll. (2007) 'Death Toll from 9/11', from http://www.arrange online.com/Obituary/memorials.asp?ObituaryID=64163480, accessed 20 September 2007.

Rapoport, D.C. (1984) 'Fear and trembling: Terrorism in three religious traditions', American Political Science Review 78(3): 658-677.

Rapoport, D.C. (2004) 'Modern terror: The four waves', in A.K. Cronin and M.L. James (eds.) Attacking Terrorism: Elements of a Grand Strategy, Washington, DC: Georgetown University Press, 46-73.

Schlesinger, H. (2000) 'The theory of insurance demand', in D. Georges (ed) Handbook of Insurance, Boston: Kluwer, pp. 131-151.

Schmidt, R. and Gerathewohl, K. (1973) 'Die Versicherung bei Gewalttätigkeiten gegen eine Gemeinschaft wobei Personen oder Sachschäden entstehen', Zeitschrift für die gesamte Versicherungswirtschaft 62: 277-317.

Swiss Re. (2006) 'Natural catastrophes and man-made disasters 2005', Sigma 2/2006 Swiss Reinsurance Company, Economic Research \& Consulting, http://media.swissre.com/documents/sigma2_ 2006_en.pdf, accessed 04 April 2011.

Tversky, A. and Kahneman, D. (1973) 'Availability: A heuristic for judging frequency and probability', Cognitive Psychology 5: 207-232.

United States Department of State. (2004) Patterns of Global Terrorism 2003, Washington, DC: U.S. Department of State.

Verfassungsschutzbericht. (2006) Annual report of the German Federal Office for the protection of the constitution, accessed 30 June 2010.

Viscusi, W.K. (1989) 'Prospective reference theory: Toward an explanation of the paradoxes', Journal of Risk and Uncertainty 2: 235-264.

Viscusi, W.K. and Evans, W. (2006) 'Behavioral probabilities', Journal of Risk and Uncertainty 32: $5-15$.

Viscusi, W.K. and O'Connor, C. (1984) 'Adaptive responses to chemical labelling: Are workers bayesian decision makers?' American Economic Review 74: 942-956.

Wilkinson, P. (1986) 'The media and terrorism: A reassessment', Terrorism and Political Violence 9: 51-64.

\section{About the Authors}

Dr Christian Thomann is a Desk Officer at the Ministry of Finance, Financial Institutions and Markets, Stockholm, Sweden.

Razvan Pascalau (PhD) is an Assistant Professor at the School of Business and Economics, State University of New York-Plattsburgh (SUNY).

Dr J.-Matthias Graf von der Schulenburg is Professor at and Director of the Institute for Risk and Insurance, Leibniz University Hannover. 